Revista Destaques Acadêmicos, Lajeado, v. 9, n. 4, 2017. ISSN 2176-3070

DOI: http://dx.doi.org/10.22410/issn.2176-3070.v9i4a2017.1652

www.univates.br/revistas

\title{
DESCRIÇÃO DO PREPARO DO CORANTE E DAS DIVERSAS UTILIZAÇÕES DO URUCUM PELO POVO XAVANTE
}

\author{
Vilianes Tsere' $u^{\prime}$ awa Tsuwaté ${ }^{1}$, Marcelo Franco Leão ${ }^{2}$
}

\begin{abstract}
Resumo: Este estudo descreve o processo de obtenção do corante do urucum e as diversas formas de uso pelo povo indígena Xavante de Mato Grosso. O objetivo da pesquisa é fortalecer os conhecimentos tradicionais sobre a utilização do urucum, o processo de transformação das substâncias, as mudanças de estado físico que ocorrem durante o preparo do corante, também saber um pouco da mitologia do povo Xavante sobre o urucum. Este estudo descritivo e exploratório, de abordagem qualitativa, foi realizado nos anos de 2014 e 2015. Além das observações a campo, com intuito de coletar maiores informações, foram realizas três entrevistas com pessoas que detém domínio amplo da cultura. O estudo permitiu constatar como é realizada a prática de preparação do corante do urucum pelos Xavantes, bem como se dão as muitas utilizações do urucum, tais como: na pintura corporal, no artesanato, nos costumes e na medicina tradicional. Além de ter permitido constatar a importância dessa planta para o povo Xavante, o estudo serviu como maneira de registro que poderá ser utilizado para fortalecimento da cultura desse povo tradicional.
\end{abstract}

Palavras-chave: Prática cultural. Povos indígenas. Pintura corporal. Tradição.

\section{INTRODUÇÃO}

Nosso país é constituído de uma natureza rica em diversidade, na qual temos a oportunidade de conviver e desfrutar deste ambiente. Das muitas espécies de plantas, podemos destacar algumas bastante utilizadas pelos povos indígenas, tais como: mangueira, pé de mamão, cará, goiabeira, pé de caju, pé

1 Graduado em Licenciatura em Ciências Matemáticas e da Natureza pela Faculdade Indígena Intercultural da Universidade do Estado de Mato Grosso (UNEMAT).

2 Graduado em Química pela UNISC e em Licenciatura em Física pela UNEMAT. Pós-graduado em Orientação Educacional (Dom Alberto) e em Relações Raciais na Educação e na sociedade Brasileira (UFMT). Mestre em Ensino (UNIVATES). Doutorando em Educação em Ciências (UFRGS). Professor do IFMT Campus Confresa. Orientador dessa pesquisa de graduação na Faculdade Indígena Intercultural da UNEMAT. 
de jaca, bocaiuva, pequi, pé de buriti, pé de jenipapo, pé de mangaba, pé de jatobá, pé de cagaiteira, milho, feijão, entre tantas outras.

Dentre tantas plantas, uma delas merece destaque por ser utilizada de forma mais intensa e em variadas maneiras pelos indígenas, que é o urucum. Essa planta é muito importante por envolver aspectos da cultura. Contudo, são poucos os registros realizados sobre os aspectos culturais dos indígenas, principalmente aqueles que poderiam também ser explorados de maneira científica. Nos estudos de Jesus, Lopes e Costa (2015), por exemplo, ao descrever detalhadamente os aspectos da pintura corporal utilizada pelo povo indígena Bakairi, também foram descritos os aspectos científicos do urucum e do genipapo.

$\mathrm{Na}$ cultura Xavante o urucum tem uma importância especial. Esta planta costuma ser utilizada por meu povo para diversas coisas, por exemplos: a raiz é usada para medicina, o caule é usava para botar o fogo e também para colocar na orelha para chamar atenção das mulheres. Sem dúvidas uma de suas principais utilizações é extrair a massa que envolve suas sementes, de cor vermelha, e usar na pintura corporal e no artesanato.

Foram muitos os motivos que me levaram estudar o urucum. Um deles é porque acredito que a pesquisa pode contribuir para fortalecer a cultura e as tradições da comunidade. Também porque acredito que este registro ajuda a divulgar minha cultura. Outro motivo se deu ao fato de que serei professor de ciências naturais e o estudo me possibilitou identificar em aspectos culturais a presença dos conceitos da ciência, ou seja, é possível ensinar ciências por meio dos fenômenos que envolvem a natureza. Percebo que nem todas as pessoas de meu povo, em especial os estudantes, conhecem as transformações e o processo de preparação da massa de corante de urucum que muito utilizamos e acredito que o registro proposto poderá levá-los a compreender o processo e entender esta ciência envolvida.

Desde quando estudei marcenaria já tinha curiosidade em conhecer mais a natureza e as possibilidades de utilizar seus recursos. Agora como sou professor das crianças reforça a necessidade de ensinar a cuidar da natureza e saber usar todas as riquezas que ela nos oferece. O estudo do urucum também vai me ajudar a ensinar a ciência envolvida na natureza.

Considerando as informações apresentadas, esta pesquisa tem como objetivos identificar as muitas formas de utilização da planta urucum pelo povo Xavante e descrever o processo de obtenção da massa (corante) do urucum utilizada em processos de pintura corporal e artesanato.

O presente estudo é um recorte do Trabalho de Conclusão de Curso de Licenciatura em Ciências Matemáticas e da Natureza, apresentado para a Faculdade Intercultural Indígena da Universidade do Estado de Mato Grosso (UNEMAT), cuja defesa ocorreu no ano de 2016. 
Como forma de organização, esse texto está estruturado em cinco sessões. Após a introdução, são apresentadas as características básicas sobre a planta urucum tendo suporte na literatura já consolidado sobre o assunto. Em seguida são apresentados os caminhos metodológicos adotados no estudo. Os resultados obtidos na investigação foram apresentados na seguinte sequência: origem e costumes envolvendo o urucum, processo de preparação do corante e formas de utilização do urucum pelo povo Xavante.

\section{CARACTERÍSTICAS DO URUCUM}

O nome científico do urucum, segundo Jesus, Lopes e Costa (2015), é Bixa orellana L.. Na língua materna, que é a língua Xavante, chamamos a planta de bö. As substâncias que formam este pigmento vermelho são: clorofila, carotenoides com destaque para a bixina (responsável pela coloração vermelha) e de sais de oxônio (COSTA; CHAVES, 2005).

O urucum é uma planta de classe magnoliopsida, de ordem malvales, de família bixaceae, do gênero bixa e da espécie bixa orellana, a semente é monocotiledônea, sendo nativa da América tropical, que chega a atingir altura de seis metros (ROHDE; SILVEIRA; VARGAS, 2006).

Segundo Alves (2005), o urucuzeiro é um arbusto que apresenta grandes folhas de cor verde-claro e flores rosadas com muitos estames. Seus frutos são cápsulas armadas por espinhos maleáveis, que se tornam vermelhas quando ficam maduras.

Nos estudos de Costa e Chaves (2005), é dito que o pé de urucum é um arbusto nativo do Brasil e de outras regiões tropicais do planeta. Este arbusto é bastante encontrado em regiões de cerrado como a que minha comunidade está localizada. O pé de urucum pode ser observado na Figura 1.

Figura 1: Aspectos do arbusto urucuzeiro.

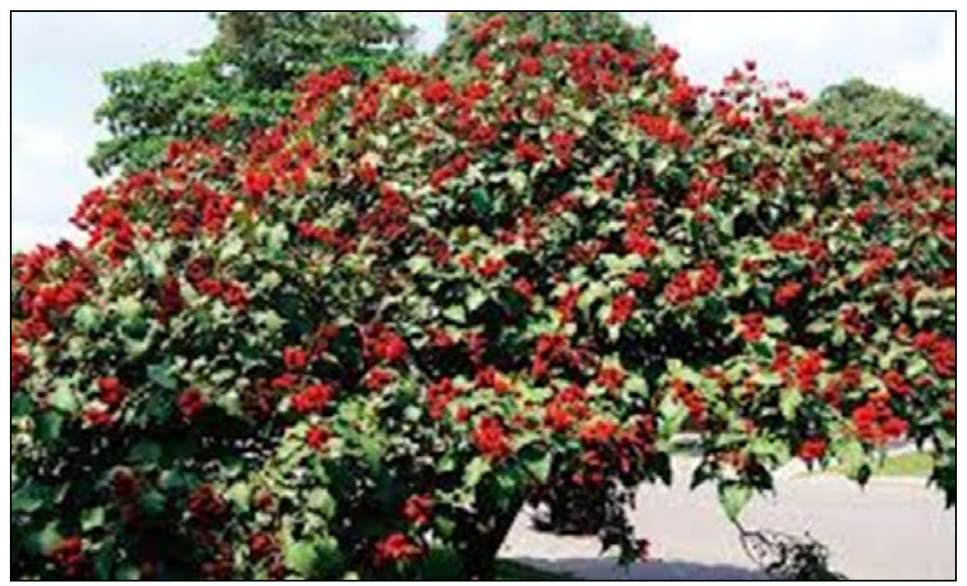

Fonte: Disponível em:<produto.mercadolivre.com br> Acesso em: 06 fev. 2016. 
O principal produto extraído do urucuzeiro é a bixina, que é uma substância que se encontra na camada de cobertura das sementes. Então se abrem e revelam pequenas sementes dispostas em série, de trinta a cinquenta por fruto, envoltas em arilo também vermelho. "Urucu" e "urucum" originamse do tupi transliterado $u r u$ 'ku, que significa "vermelho", numa referência à cor de seus frutos e sementes. Estas características podem ser visualizadas na Figura 2.

Figura 2: Aspectos do fruto e das sementes de Urucum.

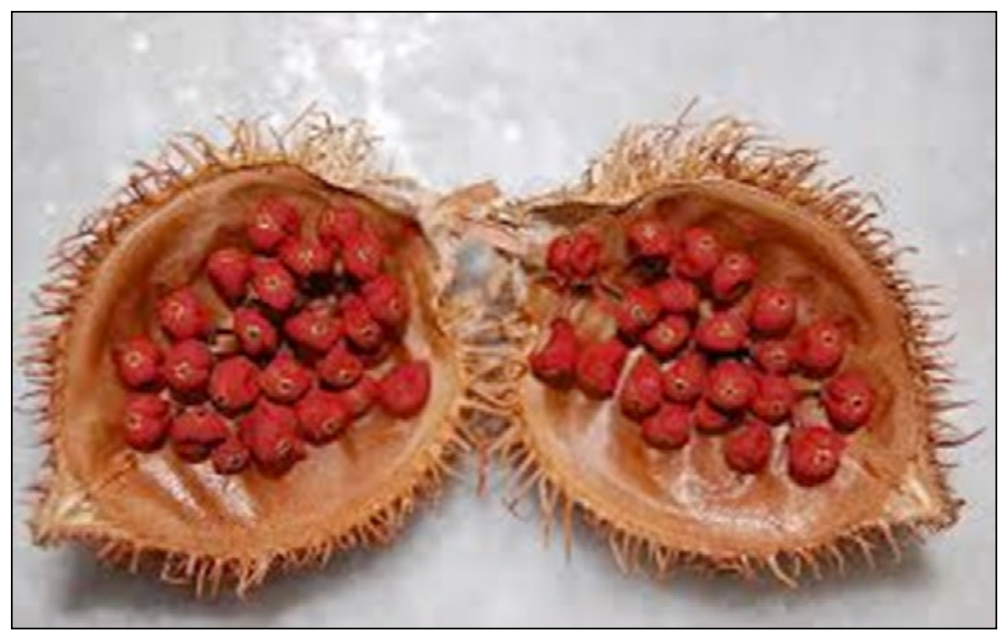

Fonte: Disponível em:<natural.enternauta.com.br> Acesso em: 06 fev. 2016.

A plantação de urucum pode acontecer somente em meses de chuva e inverno, porque no tempo da seca é fácil secar a muda ou morrer. O tempo da colheita usualmente ocorre nos meses de junho e julho. A planta tem que ficar sempre limpa, porque pode sufocar com outra planta. O plantio do urucum está acontecendo muitas vezes no dia da lua cheia.

Segundo Pinto (2008), as sementes são colhidas nos meses de maio e junho. As sementes são raladas em peneiras finas e fervidas em água para formar uma pasta. Com esta pasta são feitas bolas que são envolvidas em folhas, e guardadas durante todo o ano para as cerimônias de tatuagem. O corante extraído do urucum também é usado para tingir os cabelos e na confecção de mascarás faciais.

O corante extraído do pericarpo das sementes de urucum (Bixa orellana L.), um arbusto nativo do Brasil e de outras regiões tropicais do planeta recebe a denominação internacional de annatto, sendo largamente utilizado em várias partes do mundo em escala industrial, por conferir coloração atraente a uma extensa gama de produtos manufaturados. 
Pinturas com urucum são feitas desde tempos muito remotos pelos indígenas que abitavam do México até o Paraguai, incluído América Central e Antilhas (PINTO, 2008). Os estudos de Rohde, Silveira e Vargas (2006), historicamente o urucum vem sendo utilizado pelos povos de diversas maneiras. Cabe aqui ressaltar que, na cultura Xavante, o mesmo corante utilizado na pintura corporal também serve para enfeitar o artesanato.

\section{PROCEDIMENTOS METODOLÓGICOS}

Este estudo caracteriza-se como uma pesquisa etnográfica, descritiva e exploratória, cuja abordagem é qualitativa. Segundo Angrosino (2009), a etnografia pode ser compreendida como um tipo de pesquisa que investiga as práticas sociais, os costumes, ou ainda a forma de viver, ou seja, é um estudo que permite compreender determinada cultura por meio da observação direta daquele determinado grupo de pessoas escolhido para investigação. A pesquisa envolveu a comunidade Xavante na região São Marcos, no município de Barra do Garças-MT. Sua realização ocorreu no decorrer dos anos de 2014 e 2015.

Para coletar dados, foram realizadas entrevistas semiestruturadas com três pessoas importantes de aldeias diferentes. Uma delas foi o cacique da aldeia Cristo Rei. Este senhor já desenvolve sua função há dezesseis anos. O mesmo falou para mim que é melhor publicar esse estudo quando tiver pronto, porque tem muita gente que não conhece a cultura e precisa aprender este processo do urucum, principalmente a geração mais nova.

Outro entrevistado foi o cacique da aldeia Jardim das Oliveiras, que coordena sua comunidade há cinco anos. Também, foi entrevistada uma senhora que atua como professora do Ensino Médio da Escola Estadual Indígena Dom Felippo Rinaldi, da aldeia São Marcos. Ela exerce suas atividades há mais ou menos vinte e três anos.

As entrevistas foram feitas na língua materna, ou seja, na língua do povo Xavante. Então a primeira entrevista foi no dia treze de agosto, outro no dia vinte e seis de agosto, e o último, foi no dia oito de novembro. Todas as entrevistas foram realizadas em dois mil e catorze.

Todos os entrevistados concordaram em participar da pesquisa após serem informados dos objetivos e finalidades da mesma e autorizaram a divulgação de suas respostas e dados. Cabe aqui apontar que os entrevistados assinaram os Termos de Consentimento Livre e Esclarecido (TCLE) e as lideranças das comunidades assinaram a Carta de Anuência autorizando a realização do estudo. As entrevistas foram concedidas na língua materna. As mesmas foram gravadas em áudio para posteriormente serem transcritas e traduzidas na Língua Portuguesa.

Também foram realizadas observações para coletar dados sobre o objeto em estudo. Utilizou-se como instrumento um diário que permitiu o registro de informações importantes sobre a produção da pasta de urucum. Este diário 
acompanhou o pesquisador durante as observações. Além das anotações, foram tiradas fotografias dos acontecimentos e produzidas algumas imagens para ilustrar as formas de utilização da planta e o processo de obtenção do corante.

\section{RESULTADOS OBTIDOS NO ESTUDO}

\subsection{Origem e costumes envolvendo o Urucum}

A primeira entrevista, foi com o cacique, da aldeia de Cristo Rei, sendo um primeiro questionamento referente a origem da planta de urucum. Segundo ele: "A planta do urucum existia desde os primeiros antepassados do povo Xavante, ou seja, o urucum teve origem desde quando o povo Xavante passou a existir" (ENTREVISTADO 1). Na ocasião, também foi perguntado para ele sobre o uso do urucum e de como se prepara o corante do urucum, porém esses dados serão apresentados mais adiante.

Ainda segundo o cacique: "Antigamente, aconteciam coisas como que milagres, vindas do céu, ou seja, desciam do céu e eram dadas ao povo Xavante. Então todas as coisas já existiam, já foram feitas, vieram feitas, mas isso foi só antigamente" (ENTREVISTADO 1). Depois das brigas, andanças, e outras coisas ruins que aconteceram com o povo, isso foi perdido e ninguém mais lembrava disso, nem imaginava. Tiveram muitas coisas que aconteceram e que fizeram parte da cultura Xavante, porém nem ele não podia mais lembrar de todas. O cacique reforçou que não pode falar mentiras, não vai inventar nada como os outros inventam, ou seja, o que ele souber é que vai contar.

Então o cacique começou a falar da origem do urucum. Ele contou que antigamente "o povo Xavante vivia com o corpo pintado de urucum, desde as primeiras gerações, o que era muito bonito" (ENTREVISTADO 1). Outra característica relatada foi de que a planta do urucum já existia na natureza, ou seja, não foi importado de outros países pelo não indígena.

\subsection{Processo de preparação do corante}

Sobre o preparo do corante para as pinturas corporais, o cacique falou sobre a maneira com que acontecia, de como cozinhava o urucum, falando que "antigamente se cozinhava dentro da vasilha feita de barro" (ENTREVISTADO 1). Antes porém, ainda segundo ele, era preciso pintar as beiradas da vasilha para não quebrar facilmente, também para não se misturar com outro tipo de líquido, pintava com corante de jenipapo.

Da aldeia São Marcos, foi entrevistada uma senhora anciã que descreveu a respeito de todo o processo, desde a colheita do fruto de urucum, de como se prepara o corante do urucum, até ficar pronto para a pintura. Segundo costume do povo Xavante, para a colheita, "a família se une para fazer colheita dos frutos, porque colher sozinha ninguém daria conta, porque a planta é alta, 
tem algumas que chegam a seis metros ou um pouco menos, por isso é difícil" (ENTREVISTADA 2).

Então a família se une, pois tem gente que tenta alcançar os galhos do alto, mas não se sobre na planta, porque o arbusto do urucum não é resistente. Assim, a solução é utilizar uma escada para colher só os frutos maduros, sem danificar as plantas, porque se prejudicar não vai dar mais frutos, e consequentemente nem a massa de urucum. O restante dos familiares ficam no chão para coletar os derrubados (ENTREVISTADA 2). Sobre o tempo da colheita, a entrevistada relatou que geralmente ocorre nos meses de junho e julho. Ainda segundo ela, também é esse o melhor período para extrair o corante do urucum. A colheita está representada na Figura 3.

Depois da colheita, abrem-se os frutos para tirar sementes. Para tirar semente não é fácil, pode inclusive dar dor na coluna, no pescoço por isso o processo envolve no máximo seis pessoas abrindo os frutos. Outra coisa bem importante a ser registrada, é que este fruto não pode ficar muito tempo guardado, porque se ficar secará a semente ou sua cápsula, então não prestará mais para abrir e socar a semente. Por esse motivo, aquela pessoa que abre os frutos geralmente trabalha o dia inteiro e a noite inteira para que as sementes não sequem. Esse processo pode levar no máximo três dias. As sementes são coletadas separadamente (FIGURA 3).

Figura 3: Colheita dos frutos.

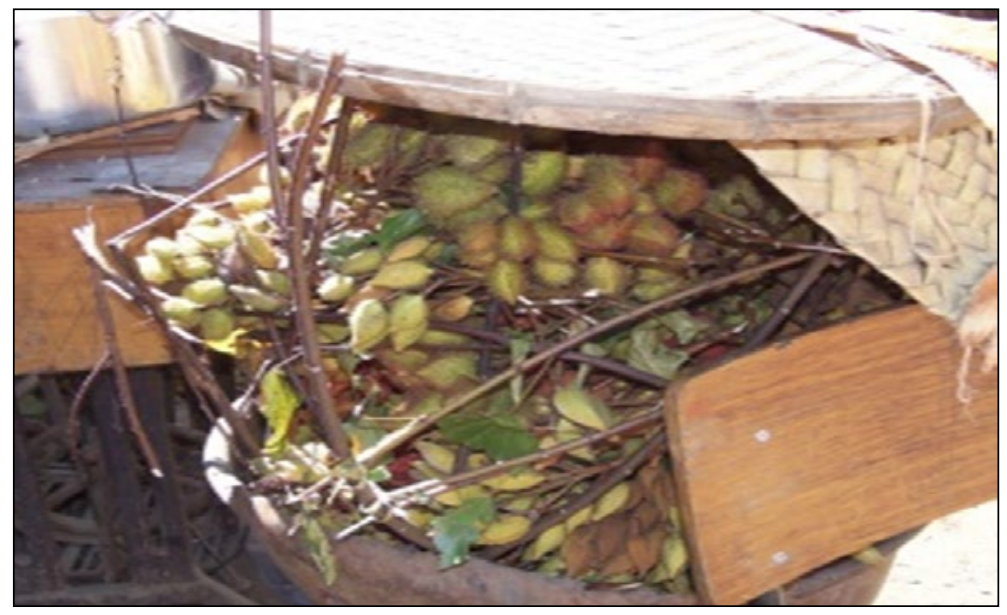

Fonte: Acervo pessoal de Tserewatsa, N. (2015).

Em seguida inicia outro processo, no qual as sementes são colocadas sobre um pedaço de couro de veado para serem socadas com o auxílio de pedras. Esse processo ajuda a retirar, a desgrudar, a extrair o pigmento do urucum. A entrevistada reforça que: "Não é fácil socar sozinha o urucum, por isso é preciso a ajuda de mais mulheres, geralmente são as filhas que ajudam 
a mãe. Essa atividade exige que todas fiquem muito próximas para trabalhar juntas" (ENTREVISTADA 2). Devido esse processo ser longo, também não é fácil. Nessa etapa é preciso socar as sementes e despejar a água encima. $\mathrm{O}$ líquido avermelhado vai sendo separado e sobre as sementes se adiciona mais água, até ficar só um líquido de cor clara. Só assim a etapa será concluída e a parte selecionada é levada para cozimento. As primeiras etapas desse processo podem ser observadas na Figura 4.

Figura 4: Processos de maceração e separação do pigmento.

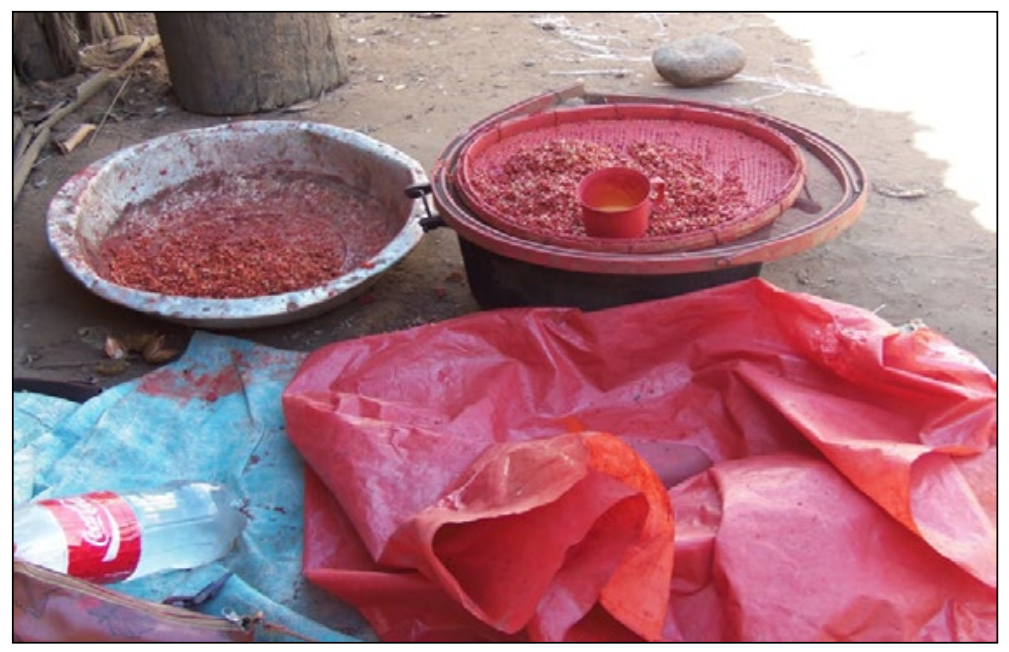

Fonte: Acervo pessoal de Tserewatsa, N. (2015).

Após socar todas as sementes, é preciso esquentar a massa para que seja extraído o líquido de urucum. A massa é despejada dentro de uma vasilha ou panela maior para que seja adicionado água. "Quem realiza essa atividade é uma mulher ou moça, porque esse costume é exclusivo das mulheres, sendo que todas elas devem aprender e assim preservar nossos costumes para o futuro" (ENTREVISTADA 2).

Durante este processo de preparo e cozimento, "a mulher faz regime para não aconteça coisa ruim, também não pode tomar muita água, nem pode comer carne. Outra regra é não poder fazer sexo, se não, estragará o brilho do urucum, acabará o pigmento vermelho e secará sozinho" (ENTREVISTADA 2). Esses são alguns costumes do povo Xavante que são observados por todos. $\mathrm{O}$ cozimento da pigmentação pode ser observado na Figura 5. 
Figura 5: Líquido do urucum, cozinhando no fogo.

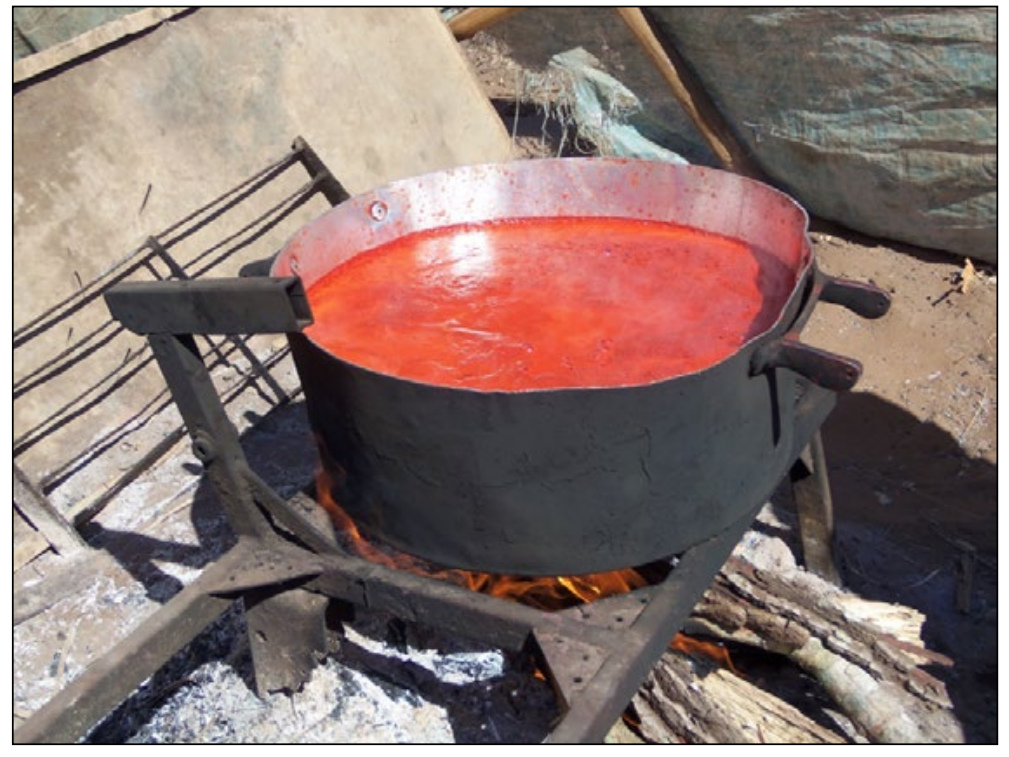

Fonte: Acervo pessoal de Tserewatsa, N. (2015).

Caso a cozinheira não cumpra essas regras, com certeza acontecerá falhas e todos perceberão. Por isso a importância de cumprir os costumes certos neste processo. A mulher que prepara essa etapa fica jejuando até que o líquido com o corante do urucum engrosse. Para que o líquido se torna mais vermelho e brilhante, é preciso adicionar uma fibra de uma árvore que é especifica da região, utilizada somente para isso. Na língua materna essa fibra se chama wedenhôrôtó e em língua portuguesa se chama a fibra de Mutamba.

Após essa etapa, utiliza-se uma substância retirada da fibra de uma árvore e que é recebe aquecimento dentro de uma panela ou vasilha para se soltar o seu produto. Esse processo de extração é do tipo aquosa a quente. A substância extraída é conhecida como wedenhôrôtó e apresenta um aspecto gelatinoso semelhante a uma clara do ovo, o que pode ser observado na Figura 6. Esse líquido extraído da fibra é adicionado ao preparo da pasta, pois interage com o pigmento do urucum por meio de reações químicas, dando consistência a mistura. 
Figura 6: Substância utilizada na produção da pasta de urucum (wedenhôrôtó).

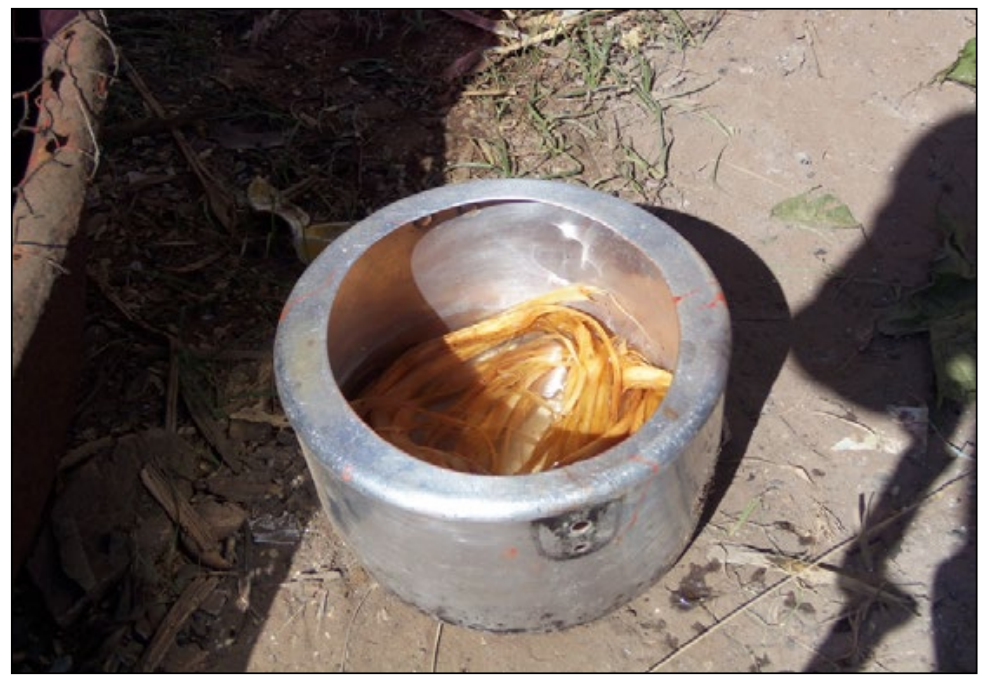

Fonte: Acervo pessoal de Tserewatsa, N. (2015).

Após o líquido com urucum ficar grosso, a mulher apaga o fogo e espera até esfriar a panela. Essa panela vai ficar no sol em cima de uma prateleira feita de vara. Porém, quando o sol estiver se pondo ela ou o marido precisam guardar dentro de casa, caso contrário estragará, se o sereno molhar também estraga, não vai prestar mais e ninguém poderá usar nas festas. O processo de secagem pode ser observado na Figura 7.

Figura 7: Massa de urucum quase pronta, deixado no sol.

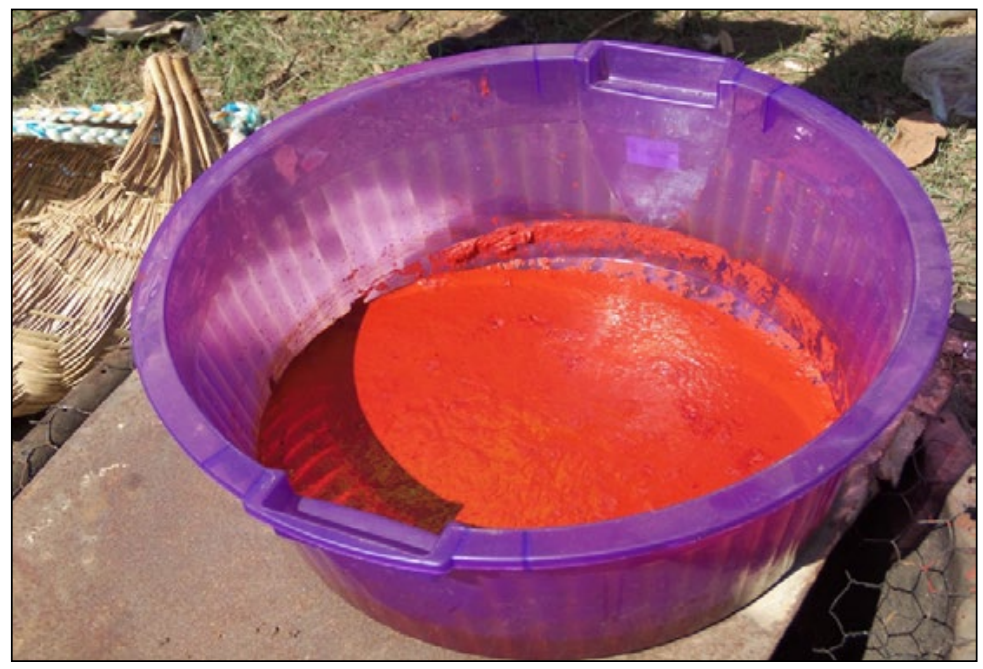

Fonte: Acervo pessoal de Tserewatsa, N. (2015). 
"Quem é responsável por moldar as bolas de urucum são os homens. Durante a transformação dentro da panela, o homem separa o que engrossou para fazer bolas" (ENTREVISTADA 2). A quantidade de bolas que resultam do processo depende da quantidade de matéria que engrossou dentro da panela, se for panela maior pode fazer quatros bolas ou cinco, mas se secar muito pode sair apenas uma ou duas (FIGURA 8). Estando as bolas prontas, o homem vai preparar as fibras de madeira para enrolar as bolas de urucum, mas esta fibra se chama na nossa língua Xavante é tsatede, porque ela é fina e é maior largura.

Conforme os estudos de Alves (2005), os pigmentos de urucum geralmente são obtidos por processos mecânicos de raspagem das sementes e atrição ou ainda por extração com solventes, porém isso varia de cultura para cultura.

Figura 8: Bola com o corante preparado de urucum.

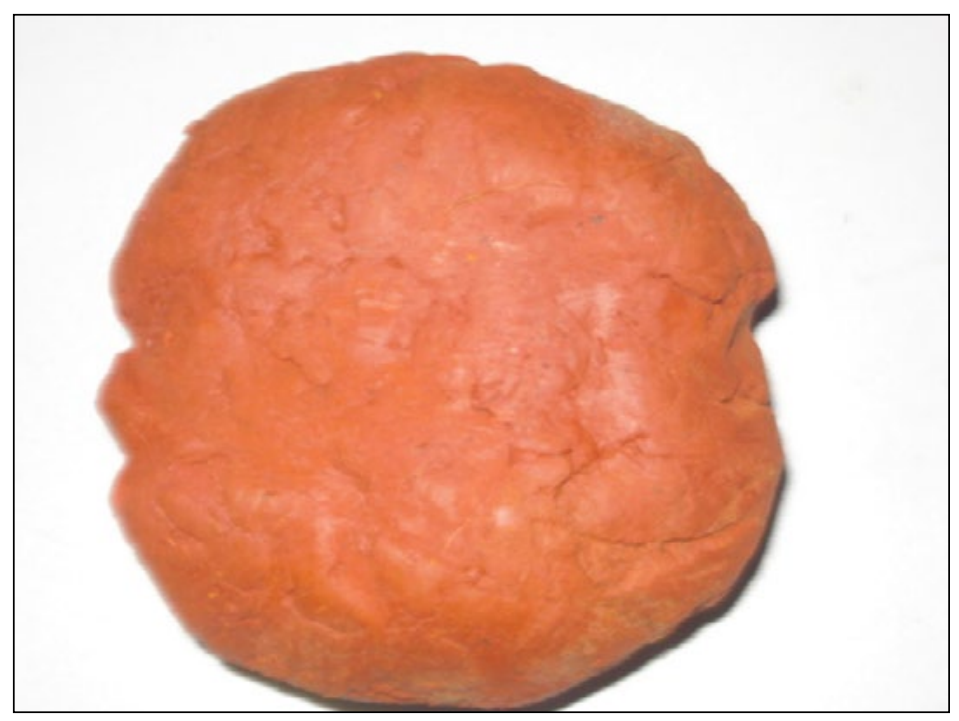

Fonte: Acervo pessoal de Tsuwaté, V. T. (2015).

O primeiro cacique entrevistado falou da utilização do urucum também. Segundo ele, para utilizar o corante na pintura corporal, é preciso mastigar a castanha de babaçu para tirar o leite (látex) e assim misturam com a massa de urucum. Essa adição acontece para facilitar o processo de tirar o corante para passar no corpo do homem (ENTREVISTADO 1). A utilização do corante do urucum com a castanha de babaçu está representada na Figura 9.

Quando acontece uma festa, os homens então são os responsáveis por desenrolar esta bola e preparar a tinta necessária para a pintura corporal. Para extrair o corante do urucum que está em pasta, é utilizado é o leite da castanha de babaçu como uma espécie de solvente. "O homem mastiga o babaçu para tirar o leite, porque é bom para tirar o pigmento vermelho, mostrar o brilho" 
(ENTREVISTADO 1). Segundo o cacique esse leite de babaçu também ajuda na hora de lavar os corpos dos indígenas depois das festas, ou seja, a tintura sai mais fácil do que ao utilizar somente água e sabão.

\subsection{Formas de utilização do urucum pelo povo Xavante}

Os povos indígenas sempre utilizaram e continuarão utilizando corantes naturais na pintura corporal. Inclusive a pintura corporal foi uma das coisas que mais a chamou atenção do colonizador português (PINTO, 2008). A utilização do urucum na pintura corporal pode ser observada nas Figuras 9, 10 e 11.

Figura 9: Pintura corporal com corante do urucum com a castanha de babaçu.

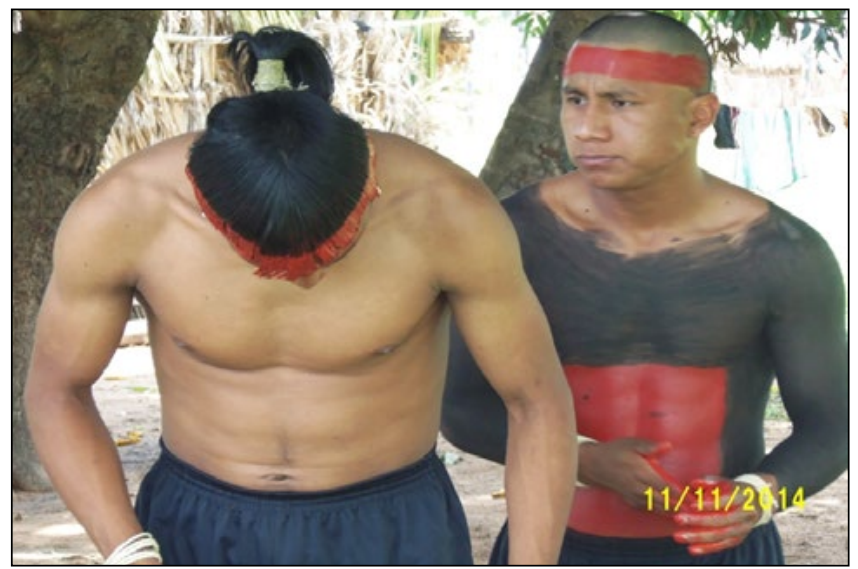

Fonte: Acervo pessoal de Tserewatsa, N. (2014).

Figura 10: Forma de pintura especifica para os adolescentes masculinos.

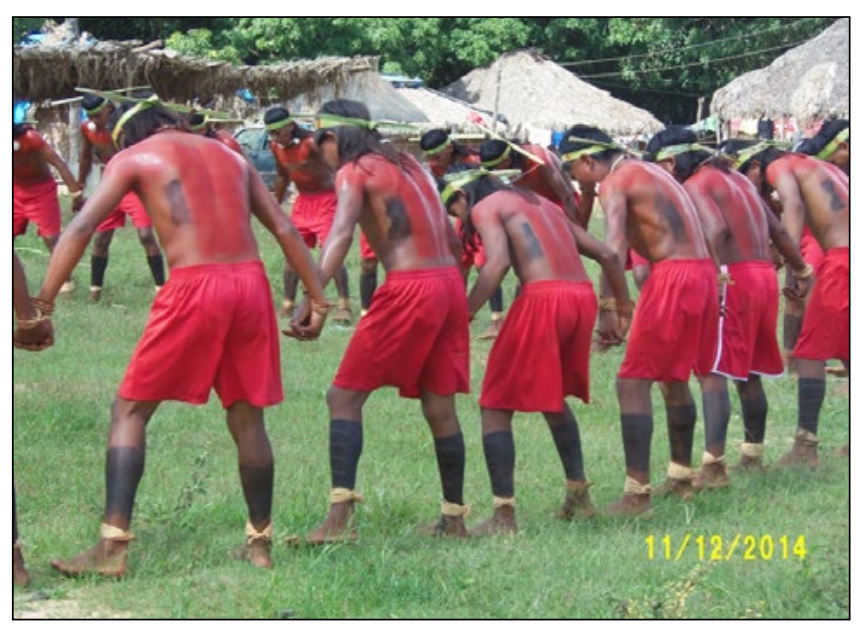

Fonte: Acervo pessoal de Tserewatsa, N. (2014). 
As pinturas corporais são diferentes para homens e mulheres, para crianças, adolescentes e adultos. Segundo os estudos de Rohde, Silveira e Vargas (2006) e de Pinto (2008), a prática da pintura corporal é bastante antiga entre os povos indígenas. Para meu povo Xavante, a pintura é uma maneira de expressar diversos sentimentos, seja de alegria, de dor, de guerra, ou ainda para marcar a transição de uma etapa da vida, a exemplo da representada na Figura 10, que ilustrou como é a pintura dos adolescentes masculinos.

Dos adultos, dos padrinhos dos adolescentes, tem pintura da noiva, tem pintura do noivo, tem pintura para casal do homem e da mulher. Tem pintura do homem corajoso. A pintura da noiva pode ser observada na Figura 11.

Figura 11: Pintura da noiva.

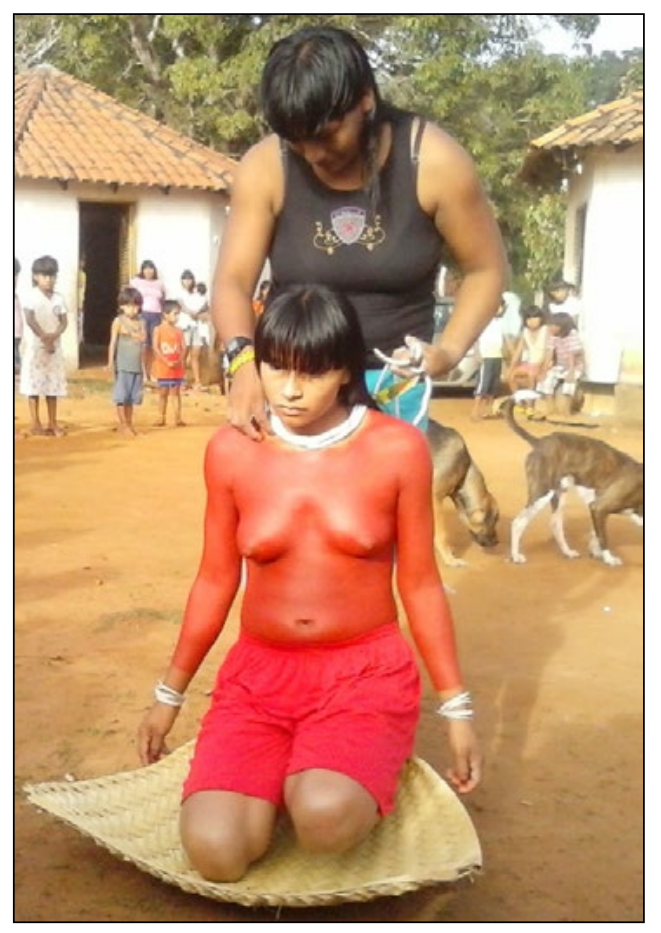

Fonte: Acervo pessoal de Tsimanawê, R. (2014).

"Para que todas essas pinturas sejam realizadas, não pode faltar as bolas com o corante de urucum preparadas, pois se isso ocorrer o povo Xavante fica desanimado, porque pode acontecer qualquer dia a festa ritual casamento e outros" (ENTREVISTADO 1). Contudo, não é só para a pintura corporal que o povo Xavante utiliza o urucum. O mesmo corante é usado para pintar o artesanato.

Esse corante do urucum serve para a pintura de wamnhõrõ que é fibra de palha de urucum, também usada no cordão ou cinto dos padrinhos dos 
adolescentes e serve também para pintura de chocalho na língua materna se chama $d z \ddot{o}$ e tem outros artesanatos. A pintura em artesanatos pode ser observada na Figura 12.

Figura 12: Artesanato que é Wamnhõrõ fibra de palha de buriti.

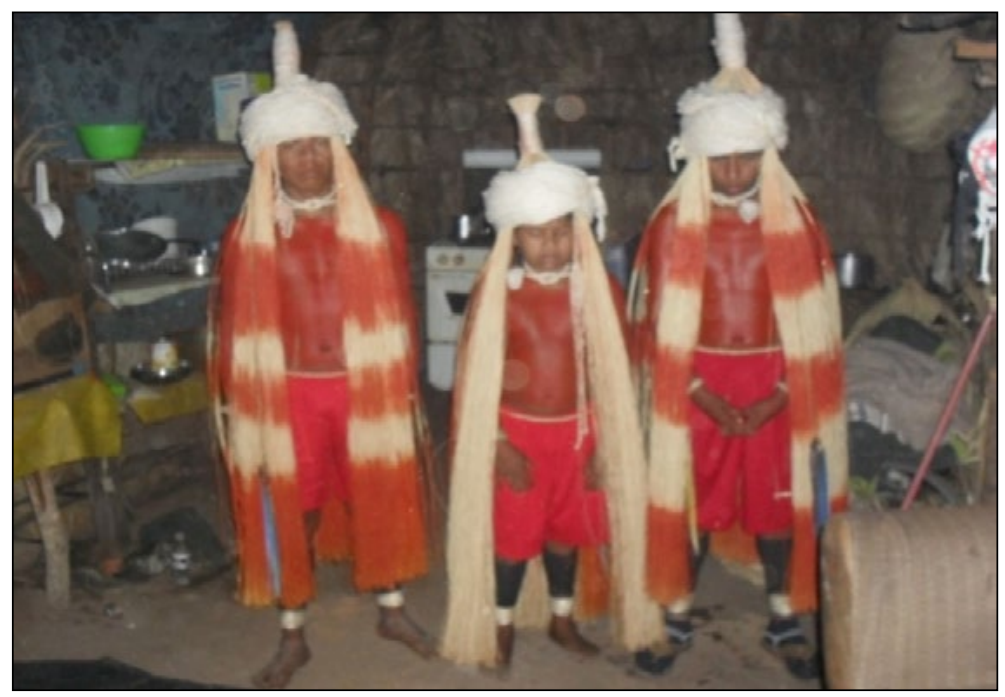

Fonte: Acervo pessoal de Tserewatsa, N. (2015).

Durante a segunda entrevista, realizada com o outro cacique, agora da aldeia Jardim das Oliveiras, foi realizado o questionamento sobre a utilização do urucu para o povo Xavante. Além das utilizações anteriormente citadas, o cacique falou do caule da planta de urucum, dizendo que "o caule serve para atrair uma mulher bonita utilizado na orelha, além de servir também para buscar os cantos no sonho" (ENTREVISTADO 3). A Figura 13 ilustra a utilização do caule de urucum como adorno atrativo que os homens Xavante utilizam para atrair a atenção das mulheres. 
Figura 13: Caule de urucum na orelha do jovem.

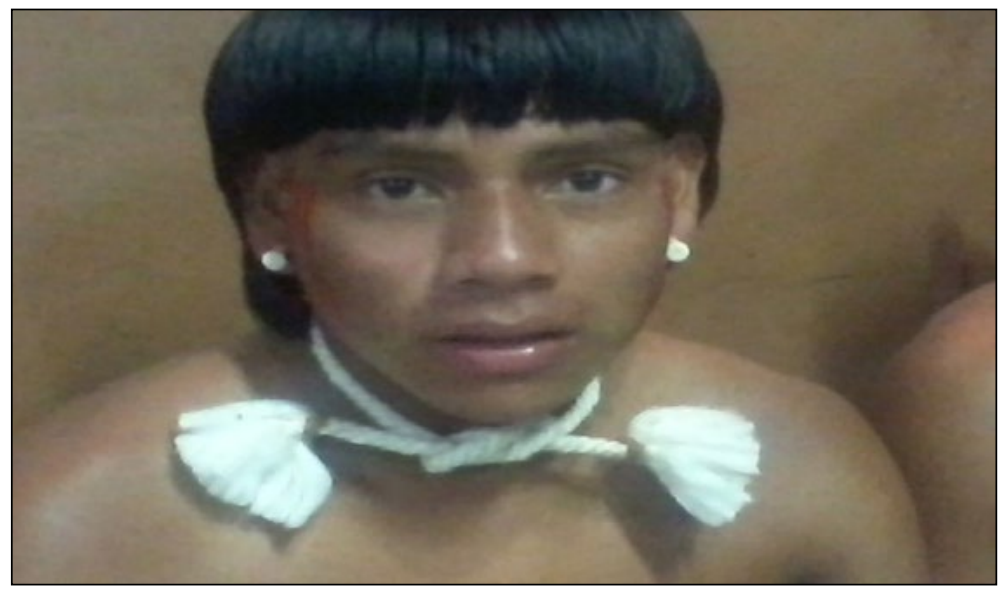

Fonte: Acervo pessoal de Tsuwaté, V. T. (2015).

O segundo entrevistado também falou que a raiz da planta de urucum serve para hemorragia por isso quando uma mulher fica com a hemorragia vai para curandeiro para medicar com esta raiz (ENTREVISTADO 3).

A planta de urucum, ainda de acordo com o segundo cacique entrevistado, é utilizada na medicina tradicional, porque os ramos e a raiz servem para estancar sangramento menstrual ou hemorragia, o caule serve para usar na orelha para chamar atenção das meninas e para em busca dos cantos pelo sonho, a massa pronta serve para cicatrizar feridas no corpo, também é utilizada para pintar os recém-nascidos para que não serem atingidos por doenças quaisquer.

$\mathrm{Na}$ atualidade, os não indígenas também utilizam bastante o urucum. Algumas dessas utilizações são: corante alimentício, para colorir manteiga, margarina queijos, doces e pescado defumado, e o seu corante principal - a bixina - em filtros solares (COSTA; CHAVES, 2005). O urucum é bastante utilizado pelos não indígenas na alimentação como corante alimentício.

O urucum também é utilizado pelos não indígenas nos bronzeadores corporais. Também foi pesquisado que o urucum é usado pelo não indígena para emagrecer, e realmente o urucum emagrece. Segundo Braga (2012), a ingestão dos pigmentos do urucum quando suas sementes são dissolvidos em água são capazes de auxiliar a queima de calorias, pois provoca um aumento grande na velocidade do metabolismo, acelerando a perda de gordura e diminui o colesterol, além de trazer saciedade para o organismo.

Neste sentido, é possível comparar com a cultura de meu povo e verificar que tem algumas semelhanças e diferenças. É parecida a pintura corporal como os bronzeadores, assim como os remédios de emagrecer e colesterol com a 
medicina tradicional que o povo Xavante utiliza. Contudo, cabe aqui lembrar que o povo Xavante não utiliza o urucum na alimentação.

Conforme Jesus, Lopes e Costa (2015), por meio do registro dos costumes de um povo sua cultura é fortalecida e socializada com as outras culturas. Por isso, ao tornar público esse processo de preparo do corante do urucum e as diversas formas que o povo Xavante utiliza essa planta, o intuito foi registrar para preservar nossa identidade, ao mesmo tempo de socializar para que as demais culturas conheçam e respeitem nossas práticas culturais.

\section{CONSIDERAÇÕES FINAIS}

Este estudo permitiu identificar as muitas formas de utilização da planta urucum pelo povo Xavante que são: pintura corporal feminina e masculina, medicina tradicional, pintura do artesanato e nos costumes tradicionais como na conquista da mulher. São muitas as formas de pinturas corporais utilizadas na cultura Xavante, porque tem pintura para guerra, tem para lazer, tem para festa tradicional, tem para festa cerimonial, tem para luto, tem pintura dos adolescentes.

O processo de obtenção da massa (corante) do urucum utilizada em processos de pintura foi acompanhado e descrito, etapa por etapa, o que também permitiu aprofundar e fortalecer o conhecimento da cultura e da natureza, principalmente ficando o registro para as novas gerações. Também este estudo pode vir ajudar a na compreensão dos fenômenos da natureza dos estudantes indígenas que estarão relacionando aspectos de sua cultura com os conhecimentos científicos.

Para finalizar, considero que o estudo foi importante para mim enquanto futuro professor de Ciências Matemática e da Natureza por ter proporcionado construir conhecimentos sobre este tema e sobre as possibilidades de ensinar as transformações que ocorrem na natureza e que estão próximas da nossa realidade. Ressalto aqui que existem muitas outras informações a serem exploradas sobre o urucum, tais como a densidade do corante, as substâncias que provocam reações químicas, entre outras coisas. Por isso sugiro a continuidade e que outras pesquisas sejam desenvolvidas sobre a temática.

\section{REFERÊNCIAS}

ALVES, R. W. Extração de corantes de urucum por processos adsortivos utilizando argilas comerciais e Colloidal Gas Aphrons. Tese de doutorado. Programa de PósGraduação em Engenharia Química do Centro Tecnológico da Universidade Federal de Santa Catarina. Florianópolis, 2005.

ANGROSINO, M. Etnografia e observação participante. Porto Alegre: Artmed, 2009. (Coleção pesquisa qualitativa). 
BRAGA, S. Urucum ajuda a emagrecer, reduz radicais livres e diminui colesterol. Editora Abril. Revista Exame, versão online de 04 jan. 2012. Disponível em: <https:/ / exame.abril.com.br/estilo-de-vida/urucum-ajuda-a-emagrecer-reduz-radicais-livrese-diminui-colesterol/>. Acesso em: 17 nov. 2015.

COSTA, C. L.; CHAVES, M. H. Extração de pigmentos das sementes de Bixa orellana L.: uma alternativa para disciplinas experimentais de química orgânica. Revista Química Nova, v. 28, n. 1, 149-152, 2005.

JESUS, Y. L.; LOPES, E. T.; COSTA, E. V. Descobrindo as Ciências na Cultura Indígena: Pinturas Corporais. Revista Curiá: Múltiplos Saberes (Online), v. 01, p. 0106, 2015.

PINTO, A. C. Corantes Naturais e Culturas Indígenas. Apostila do Instituto de Química da Universidade Federal do Rio de Janeiro, 2008. Disponível em: Acesso em:

ROHDE, D. C.; SILVEIRA, S. O.; VARGAS, V. R. A. O uso do corante urucum (Bixa orellana L.) na técnica de coloração histológica. RBAC, vol. 38, n.2, p. 119-121, 2006.

TSEEWATSA, N. Texto e Imagens. Artesanato pintado com tinta de urucum. Colheita dos frutos; Processo de maceração e separação do pigmento; Líquido do urucum, cozinhado no fogo; Matéria que faz transformação do estado é chamado "wedenhõrõtó"; Massa de urucum quase pronta, deixado no sol (2015).

TSEEWATSA, N. Imagens. O uso da castanha de babaçu para pintura corporal; Forma de pintura específica para os adolescentes. (2014).

\section{Consultores nativos}

Emílio Tsõrõté, tem 81 anos de idade, cacique da aldeia Cristo Rei.

Mercedes Ró'ó'rãnhipa Tsõrõpré, tem 43 anos de idade, professora da aldeia São Marcos na escola "Dom Filippo Rinaldi".

Sebastião A'õi'ru Tsuptó, tem 46 anos de idade, Cacique da aldeia Jardim das Oliveiras. 